\title{
Affinity Purification of Biologically Active and Inactive Forms of Recombinant Human Protein C Produced in Porcine Mammary Gland
}

\author{
Kevin E. Van Cott, Barry Williams, William H. Velander ${ }^{\star}$ \\ Department of Chemical Engineering, Virginia Tech University, Blacksburg, VA 24061, USA \\ Frank Gwazdauskas \\ Department of Dairy Science, Virginia Tech University, Blacksburg, VA 24061, USA \\ Tim Lee, Henryk Lubon and William N. Drohan \\ Jerome Holland Laboratory, American Red Cross, Rockville, MD 20855, USA
}

\begin{abstract}
Recombinant human protein C (rhPC) secreted in the milk of transgenic pigs was studied. Transgenes having different regulatory elements of the murine milk protein, whey acidic protein, were used with cDNA and genomic human protein $\mathrm{C}$ (hPC) DNA sequences to obtain lower and higher expressing animals. The cDNA pigs had a range of expression of about $0.1-0.5 \mathrm{~g} / \mathrm{milk}$. Two different genomic $\mathrm{hPC}$ pig lines have expressed 0.3 and 1-2 $\mathrm{g} /$, respectively. The rhPC was first purified at yields greater than 60 per cent using a monoclonal antibody (mAb) to the activation site on the heavy chain of hPC. Subsequent immunopurification with a calcium-dependent mAb directed to the $\boldsymbol{\gamma}$-carboxyglutamic acid domain of the light chain of hPC was used to fractionate a population having a higher specific anticoagulant activity in vitro. The higher percentages of $\mathrm{Ca}^{2+}$-dependent conformers isolated from the total rhPC by immunopurification correlated well with higher specific activity and lower expression. A rate limitation in $\gamma$-carboxylation of rhPC was clearly identified for the higher expressing animais. Thus, transgenic animals with high expression levels of complex recombinant proteins produced a lower percentage of biologically active protein.
\end{abstract}

Keywords: Transgenic; porcine; mammary gland; protein C; affinity chromatography

\section{Introduction}

Human protein $\mathrm{C}(\mathrm{hPC})$ is a plasma serine protease important to the regulation of hemostatis. The potential therapeutic value of hPC has been well documented (Comp, 1990; Mann and Bovill, 1990), but an adequate supply of hPC is limited by its low concentration in human plasma $(4 \mu \mathrm{g} / \mathrm{ml})$. The short supply of hPC from human plasma, coupled with the risk of the transmission of viral pathogens, results in hPC being a prime candidate for replacement by recombinant human protein C (rhPC) (Drohan et al., 1994b).

HPC is synthesized as an inactive precursor. A number of co- and post-translational modifications are made to the precursor (Fig. 1) (Grinnell et al., 1990; McClure et al., 1992): removal of a 42 amino acid prepropetide; vitamin $K$ dependent $\gamma$-carboxylation of nine glutamic acid residues in the first 29 amino acids of the light chain (gla domain);

\footnotetext{
- Corresponding author to whom correspondence should be addressed.

Abbreviations used: DEAE, diethylaminoethyl; EDTA, ethylene diamine tetra-acetic acid; ELISA, enzyme-linked immunosorbent assay; hPC, human protein C; HRP, horseradish peroxidase; IgG, immunoglobulin G; $\mathrm{mAb}$, moclonal antibody; NPRP, normal pooled reference plasma; PCDP, protein C-depleted plasma; PVDF, polyvinylidene difluoride; thPC, recombinant human protein C; SDS PAGE, sodium dodecyl sulfatepolyacrylamide gel electrophoresis; TBS, tris buffered saline.
}

glycosylation of four possible N-linked glycosylation sites; $\beta$-hydroxylation of $\mathrm{Asp}^{71}$; formation of 12 disulfide bridges; and a Lys ${ }^{156}-\mathrm{Arg}^{157}$ dipeptide is removed, resulting in a disulfide-linked heterodimer. Most circulating hPC therefore consists of a heavy chain $\left(M_{r}\right.$ about $\left.41 \mathrm{kDa}\right)$ connected by a single disulfide bond to a light chain $\left(M_{r}\right.$ about $21 \mathrm{kDa}$ ). Activation of hPC is catalyzed by a complex containing thrombin and thrombomodulin at the endothelial cell surface, with a dodecapeptide being clipped from the $\mathrm{N}$ terminal end of the heavy chain of hPC. Activated hPC degrades factors VIIIa and Va, inhibiting clot formation (Esmon, 1985 and 1989).

RHPC has been produced in several mammalian cell lines (Grinnell et al., 1990; Yan et al., 1990) and by transgenic animals (Drohan et al., 1994a; Morcol et al., 1994; Valendar et al., 1992a, 1992b). Morcol et al. (1994) have shown that the primary advantage of production of recombinant proteins in the mammary gland of transgenic pigs versus cell culture is the significantly higher cell density of the mammary gland than the maximum cell density possible in cell culture medium. The rhPC produced in transgenic animals appears to have a number of different subpopulations (Drohan et al., 1994a; Velander et al., 1992a), as does plasma-derived hPC (Gelfi et al., 1985; Heeb et al., 1988; Miletich and Broze, 1990).

In this work, four transgenic pig lines having steady but 
different average rhPC expression levels during a lactation ranging from 90 to $1,000 \mu \mathrm{g} / \mathrm{ml}$ milk were studied. The rhPC was purified by ion exchange and immunoaffinity chromatography to capture the majority of the total population. The purified rhPC was subsequently fractionated with a calcium-dependent monoclonal antibody, 7D7B 10, that recognizes the $\gamma$-carboxyglutamic acid domain of hPC (Orthner et al., 1989). The purpose of this study was to demonstrate a facile, immunoaffinity-based purification procedure of a recombinant protein from milk, and also to demonstrate that immunoaffinity chromatography can be a useful tool for isolating biologically active from inactive fractions of a complex recombinant protein population. This information is also useful for determining rate limitations in the biosynthesis of certain post-translational modifications.

\section{Materials and Methods}

\section{Generation of transgenic pigs}

Four different lines of transgenic pigs were used in this study. The founder transgenics were generated by the methods given in Velander et al., (1992a). Two females having a cDNA hPC construct (animals 115-6 and 81-1) and two females having a genomic hPC construct (110-1 and 122-5) were included in this study. Both the cDNAhPC genetic construct and the genomic construct cloning have been previously detailed (Droham et al., 1994a; Velander et al., 1992a).

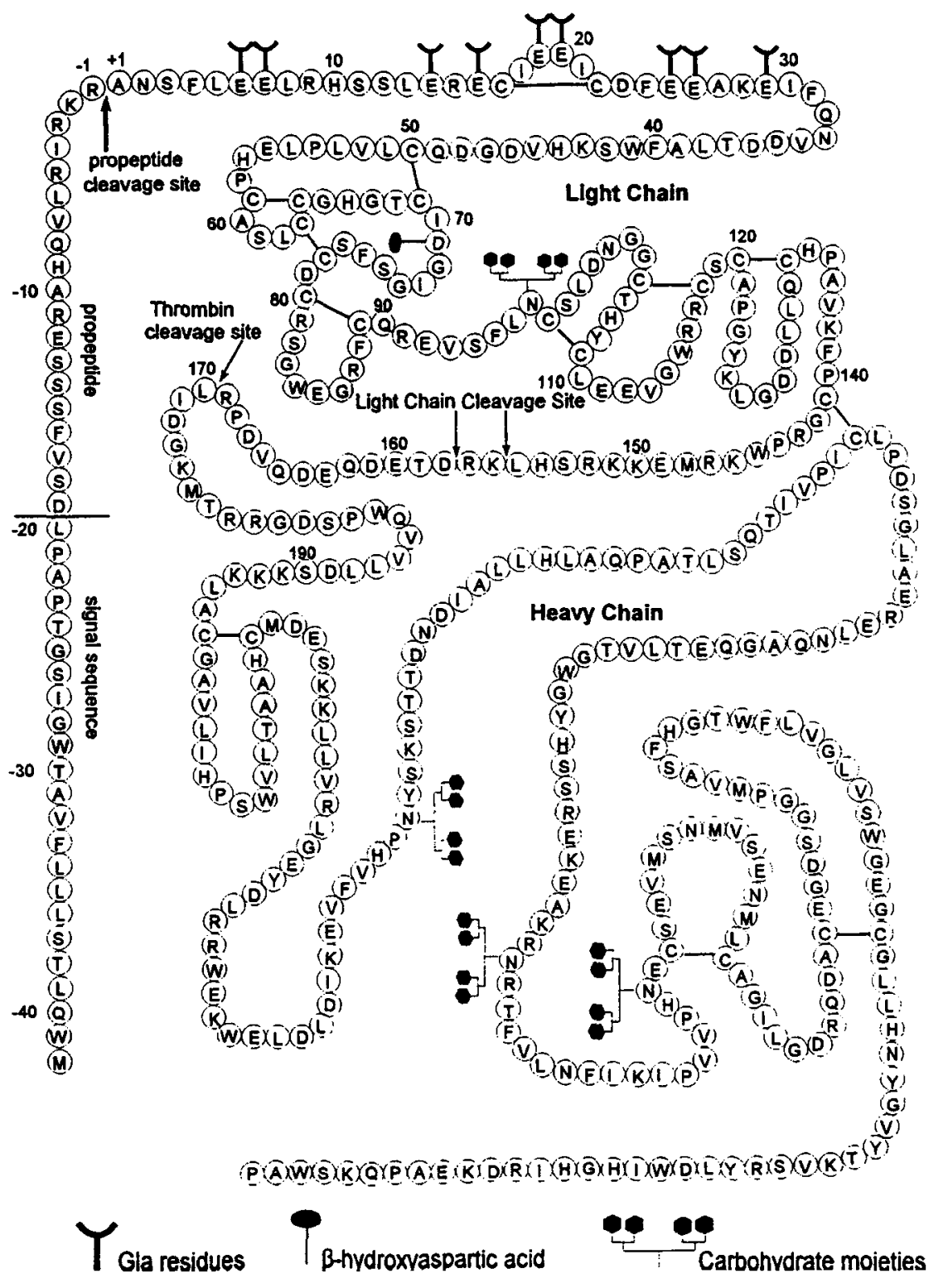

Figure 1. Schematic of hPC (based on Miletich and Broze, 1990). 


\section{Milk collection and handling}

Lactating cows were injected IM with 30-60 IU of oxytocin (Vedco Inc., St Jospeh, MO) to stimulate milk letdown. Letdown occurred 2-5 min after injection. Three to six different days during lactation were used for each pool. Immediately after collection the milk was diluted $1: 1$ with $200 \mathrm{~mm}$ ethylenediamine tetra-acetic acid (EDTA), pH 7.0 to solubilize the caseins and then stored frozen. The milk/ EDTA mixture was centrifuged for approximately $30 \mathrm{~min}$ at $3,000 \mathrm{~g}$ at $2^{\circ} \mathrm{C}$. The fat layer was skimmed from the diluted whey fraction, and the milk/EDTA mixture was centrifuged once more and filtered through Whatman \#3 filter paper (clarified milk/EDTA). All milk concentration values reported were measured from clarified whey samples using a dilution factor of 1.9 to account for EDTA addition and removal of milk fat.

\section{rhPC detection in milk}

An enzyme-linked immunosorbent assay (ELISA) was used to measure the concentration of rhPC in the milk samples. Immulon II microtiter plates (Fsicher Scientific, Pittsburg) were coated overnight with $100 \mu \mathrm{l} /$ well of $5 \mu \mathrm{g} / \mathrm{ml}$ of rabit anti-hPC (Sigma, St Louis, MO) in $0.1 \mathrm{M} \mathrm{NaHCO}, 0.1 \mathrm{M}$ $\mathrm{NaCl}$, pH 9.6 at $4^{\circ} \mathrm{C}$. Wells were then washed with $25 \mathrm{~mm}$ Tris, $50 \mathrm{~mm} \mathrm{NaCl}, 0.05 \%$ Tween 20, pH 7.2 (Tris buffered saline-Tween), and blocked for $20 \mathrm{~min}$ with $25 \mathrm{mM}$ Tris, $50 \mathrm{~mm} \mathrm{NaCl}, 0.1$ per cent bovine serum albumin (BSA), pH 7.2 (TBS-BSA) at room temperature. hPC standard (American Red Cross, Rockville, MD) and samples in the dilution buffer (TBS-BSA) were added in tripicate $(100 \mu \mathrm{l} / \mathrm{well})$ and incubated at $37^{\circ} \mathrm{C}$ for $20 \mathrm{~min}$. Wells were washed and blocked with TBS-BSA for $10 \mathrm{~min}$ at room temperature. The wells were washed and 1:1000 goat anti-hPC (American Diagnostica, Greenwich, CT) in TBS-BSA was incubated at $37^{\circ} \mathrm{C}$ for $20 \mathrm{~min}$. After washing, 1:1000 rabbit anti-goat immunoglubulin (IgG) horseradish peroxidase (HRP) conjugate (Sigma, St Louis) was incubated at $37^{\circ} \mathrm{C}$ for $20 \mathrm{~min}$. Bound chromophore was detected with O-Phenylenediamine substrate (Abbot, Chicago) at $490 \mathrm{~nm}$ using an EL308 Bio-Tek Microplate reader.

\section{Purification of rhPC from milk}

Clarified whey was diluted with two parts chilled deionized water and loaded columnwise at $1 \mathrm{~cm} / \mathrm{min}$ onto a Diethyl Sepharose FF (Pharmacia, Uppsala, Sweden) column. The column was washed with TBS $(25 \mathrm{~mm}$ Tris- $\mathrm{HCl}, 50 \mathrm{~mm}$ $\mathrm{NaCl}, 0.02$ per cent sodium azide, $\mathrm{pH}$ 7.2) until a steady baseline abosrbance $\left(A_{280 n m}\right)$ was reached. The rhPC was then eluted from the DEAE column with TBS- $0.25 \mathrm{M} \mathrm{NaCl}$ ( $25 \mathrm{~mm}$ Tris- $\mathrm{HCl}, 0.25 \mathrm{M} \mathrm{NaCl}, 0.02$ per cent sodium azide, $\mathrm{pH} 7.2$ ), and directly loaded onto the $12 \mathrm{~A} 8-8861-\mathrm{mAb}$ immunoaffinity column (at $1 \mathrm{~cm} / \mathrm{min}$ ) connected in tandem to the DEAE column. The murine monoclonal antibody (mAb) 12A8-8861 was produced from hybridoma cells in bioreactors (Kang et al., 1992). The 12A8-8861-mAb was anchored on Emphaze (a gift from 3M Bioapplications, St Paul, MN) according to the procedure given in Subramanian et al. (1994). The 12A8-8861-mAb binds to the activation region of hPC. After loading, the 12A8-8861-mAb immunoaffinity column was washed with TBS- $0.25 \mathrm{M} \mathrm{NaCl}$ and bound rhPC was eluted with a pH 10 buffer $(0.1 \mathrm{~m}$ $\mathrm{Na}_{2} \mathrm{CO}_{3}, 0.15 \mathrm{M} \mathrm{NaCl}, 0.02$ per cent sodium azide). The $\mathrm{pH} 10$ fraction was immediately brought to neutral $\mathrm{pH}$ by the addition of Tris- $\mathrm{HCl}$. The immunoaffinity column was then regenerated with $2 \mathrm{M} \mathrm{NaSCN}$ and $4 \mathrm{M} \mathrm{NaCl}$. Bound whey proteins remaining on the DEAE column were eluted with $1 \mathrm{M} \mathrm{NaCl}$, and the column was regenerated with $4 \mathrm{M}$ $\mathrm{NaCl}$. All chromatographic fractions were analyzed by ELISA for rhPC.

\section{D7B10 Fractionation}

The $\mathrm{pH} 10$ elution products were further fractionated using a 7D7B10-mAb immunoaffinity column. The mAb 7D7B10 binds to the light chain of hPC in the presence of EDTA and elutes fully $\gamma$-carboxylated hPC in the presence of calcium (Orthner et al., 1989). The immunosorbent was made by anchoring the $\mathrm{mAb}$ to Emphaze at a final density of $1 \mathrm{mg}$ $\mathrm{mAb} / \mathrm{ml}$ swollen gel. The column was equilibrated in TBS$25 \mathrm{~mm}$ EDTA before purification. The neutralized $\mathrm{pH} 10$ products were mixed 1:1 with TBS-25 mM EDTA, $\mathrm{pH} 7.2$, and loaded on the 7D7B10 column at $1 \mathrm{~cm} / \mathrm{min}$. The columns were loaded with $\mathrm{pH} 10$ products having five times the maximum capacity of rhPC, washed with TBS, and bound rhPC was eluted with TBS- $25 \mathrm{mM} \mathrm{CaCl}_{2}$, followed by regeneration with $2 \mathrm{M} \mathrm{NaSCN}$ and then $1 \mathrm{M} \mathrm{NaCl}$. The calcium and thiocyanate peaks were analyzed by ELISA for rhPC, and the percentage of the total rhPC bound eluted in the calcium peak was determined from the sum of calcium, thiocyanate and $\mathrm{NaCl}$ products.

\section{SDS PAGE and Western Blots}

Silver-stained sodium dodecylsulfate-polyacrylamide gel electrophoresis (SDS PAGE) was used to visualize the proteins in the chromatographic fractions. Gradient gels of 9-18 per cent were poured in Bio Rad Protean IIxi $16 \times 20 \mathrm{~cm}$ cassettes. The total protein concentration of the crude chromatographic fractions was estimated by measuring the $\mathrm{OD}_{280 \mathrm{~nm}}$ and assuming an extinction coefficient of $1 \mathrm{ml} / \mathrm{mg}$. The Bio Rad dye-binding assay using bovine casein in $0.16 \mathrm{M}$ lactose as a standard was also used and similar results for total protein concentration were found relative to that obtained using the $\mathrm{OD}_{280 \mathrm{~nm}}$ method. A total of $4 \mu \mathrm{g}$ of total protein was applied to the wells for all crude fractions. Purified fractions of rhPC were loaded at $0.5 \mu \mathrm{g}$ (non-reduced and $1 \mu \mathrm{g}$ (reduced). Molecular weight markers were purchased from Bio Rad.

For western blots, the proteins were electrophoresed in 9-18 gradient gels as described earlier. Non-reduced samples were loaded at $0.25 \mu \mathrm{g} / \mathrm{well}$; reduced samples were loaded at $0.5 \mu \mathrm{g} / \mathrm{well}$. The proteins were transferred to Polyvinylidene difluoride membranes (Bio Rad). The blocking buffer used was TBS/0.05 per cent Tween/0.5 per cent casein. The westerns were then developed with goat-antihPC (American Diagnostica) (1:1000 dilution in TBS/Tween/casein, incubated for $30 \mathrm{~min}$ at $37^{\circ} \mathrm{C}$ ), rabbit- 
anti-goat IgG HRP conjugate (Sigma) and the metal-enhanced DAB kit (Pierce, Rockford, IL). Bio Radprestained broad-range molecular weight markers were used in western blots.

\section{APTT Activity Assay}

The biological activity of the purified rhPC fractions was measured by the ability of the rhPC to prolong the activated partial thromboplastin time (APTT) of protein C immunodeficient plasma (Martinoli and Stocker, 1986). Samples of the $\mathrm{pH} 10$ and calcium peaks were diafiltered in Centricon 10 diafiltration units. Four times the original sample volume

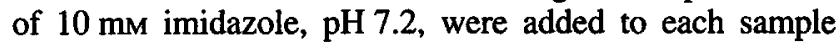
followed by a reconstitution with APTT assay buffer ( $50 \mathrm{~mm}$ imidazole, $0.1 \mathrm{M} \mathrm{NaCl}, 0.1$ per cent BSA, 0.01 per cent Tween $20, \mathrm{pH} 7.4$ ) to approximately 2 units $\mathrm{rhPC} / \mathrm{ml}$. hPC activator (Protac, American Diagnostica, Greenwich, CT) was reconstituted to $1 \mathrm{U} / \mathrm{ml}$ and $5 \mathrm{ml}$ was added to each vial of PTT Automate 5 (American Bioproducts). Protein Cdepleted plasma (PCDP; Sigma) and normal pooled reference plasma (NPRP, Sigma) were used in the assay. Briefly, $0.1 \mathrm{ml}$ of PCDP, $0.1 \mathrm{ml}$ of sample in assay buffer, and $0.1 \mathrm{ml}$ of PTT/Protac were added to the assay tubes. The tubes were incubated at $37^{\circ} \mathrm{C}$ for $3 \mathrm{~min}$, and then $25 \mathrm{~mm}$ calcium chloride was added, and the clot formation time was measured using an Elektra 750. Each sample was run in duplicate, with the average of clotting times for two or three dilutions of each sample reported. A standard curve (hPC Units versus time) was constructed using NPRP doped into PCDP to a total volume of $0.1 \mathrm{ml}$, followed by the addition of $0.1 \mathrm{ml}$ of assay buffer and $0.1 \mathrm{ml}$ PTT/Protac. A value of $1 \mathrm{U} / \mathrm{ml}$ plasma $(4 \mu \mathrm{g} / \mathrm{ml})$ in NPRP was assumed. Relative specific activities of rhPC to that of hPC were calculated by regression analysis of APTT clotting times.

\section{Results}

Table 1 shows the average daily expression levels of rhPC in the milk of the transgenic pigs. The two females transgenic for the cDNA-hPC (animals 115-6 and 83-1) had average expression levels of rhPC in milk of about $90 \mu \mathrm{g} / \mathrm{ml}$ and $390 \mu \mathrm{g} / \mathrm{ml}$, respectively. The two females transgenic for the genomic-hPC (animals $110-1$ and 122-5) had average expression levels of rhPC in milk of about $280 \mu \mathrm{g} / \mathrm{ml}$ and about $1 \mathrm{mg} / \mathrm{ml}$, respectively.

\begin{tabular}{lccc}
\hline Table 1. Average rhPC expression levels of transgenic pigs in \\
this study \\
Pig & Gene construct & Lactation & $\begin{array}{c}\text { Average rhPC expression level } \\
(\mu \mathrm{g} / \mathrm{ml} \text { milk) }\end{array}$ \\
no. & CDNA & 2nd & 90 \\
$115-6$ & CDNA & 2nd & 390 \\
$83-1$ & Genomic & 2nd & 280 \\
$110-1$ & Genomic & 1st & 960 \\
$122-5$ & Gst
\end{tabular}

- Protein C values were measured by polyclonal ELISA. The average of at least three daily samples was used for each pool.
A SDS PAGE of a representative purification process of rhPC from pig 110-1 clarified milk/EDTA is shown in Fig. 2. Initial total protein levels in the transgenic milk samples ranged from $60-80 \mathrm{mg} / \mathrm{ml}$ (as measured by $\mathrm{OD}_{280 \mathrm{~m}}$ ). The caseins $\left(M_{r}\right.$ about 27-30 kDa) are the most difficult proteins to remove from the $\mathrm{pH} 10$ product. Contamination by caseins is significant (up to approximately 20 per cent as judged by silver stain SDS PAGE) if the salt concentration of the feed to the immunoaffinity column is less than $0.25 \mathrm{M}$ $\mathrm{NaCl}$ (data not shown). By directly loading the $0.25 \mathrm{M} \mathrm{NaCl}$ eluate from the DEAE column, weak ionic interactions between rhPC, caseins, and/or the immunoaffinity column are lessened, and a purer product is obtained (Fig. 2, lane 5). The yields of rhPC in the $\mathrm{pH} 10$ fraction ranged from $65-80$ per cent of the total rhPC detected in the product fractions. The majority of rhPC not eluted in the $\mathrm{pH} 10$ product was acounted for in the flow-through of the 8861-mAb column and the $2 \mathrm{M} \mathrm{NaSCN}$ fraction.

A SDS PAGE and western blot of all the purified $\mathrm{pH} 10$ eluates are given in Figs 3 and 4, respectively. The purity of the rhPC in the $\mathrm{pH} 10$ eluate is estimated to be greater than 98 per cent, as judged by densitometric analysis of the silver-stained SDS PAGE of the non-reduced samples. The longer gradient gels used in this work significantly improve the resolution of the different populations of rhPC and hPC. The non-reduced samples in Figs $3 a$ and 4 all show heterogeneity in the total rhPC population, with three to five

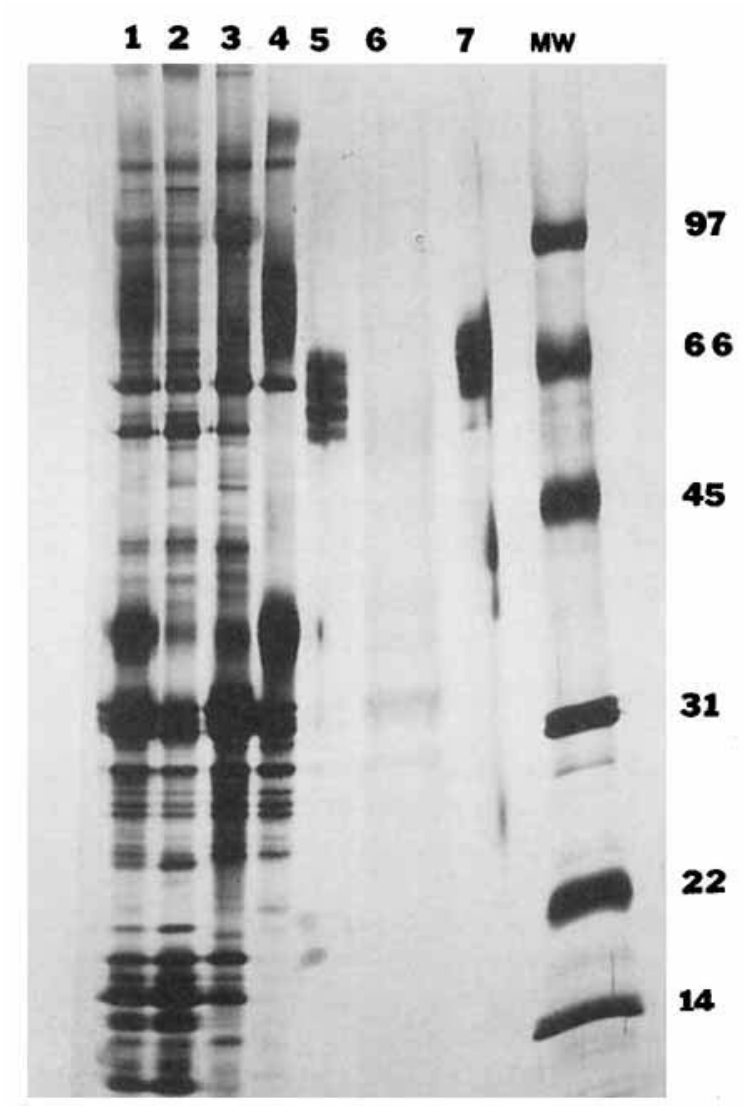

Figure 2. 9-18 per cent Silver-stained SDS PAGE of purification process for transgenic pig 110-1. Lane 1: clarified milk/EDTA feed; lane 2: DEAE column flow through; lane 3: 12A8-8861 column flow through; lane 4: $1 \mathrm{M} \mathrm{NaCl}$ DEAE eluate; lane 5: $\mathrm{pH}$ 10 product; lane 6: 12A8-8861 column 2 м NaSCN eluate; lane 7, hPC reference from plasma. 


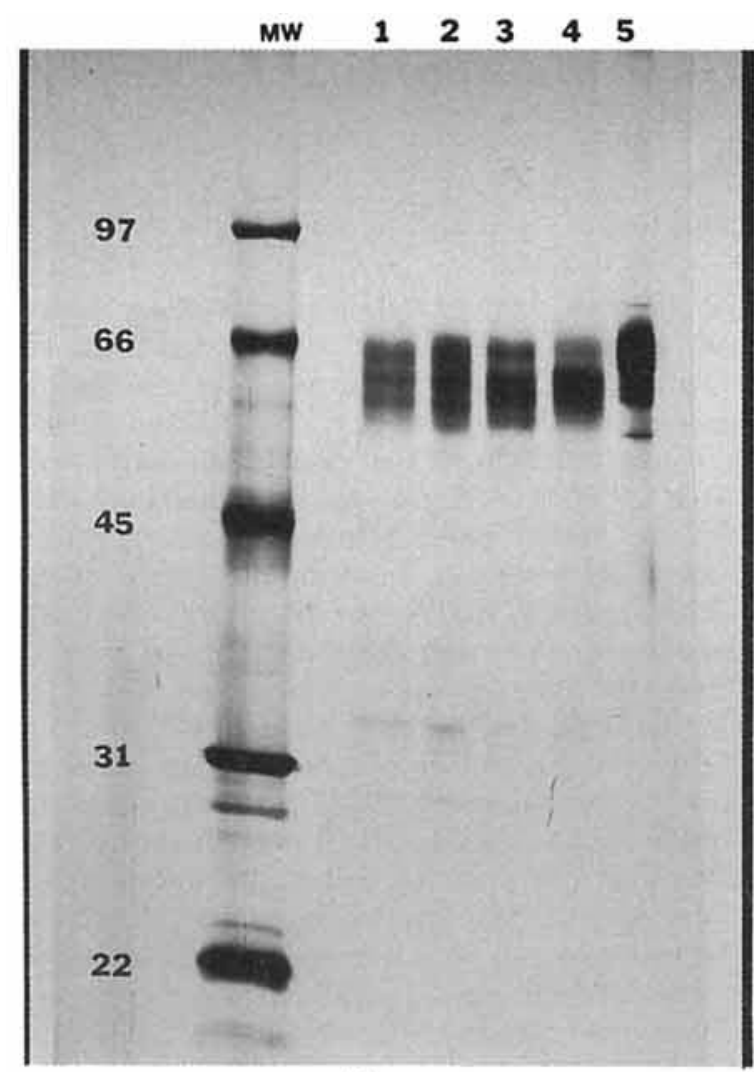

(a)

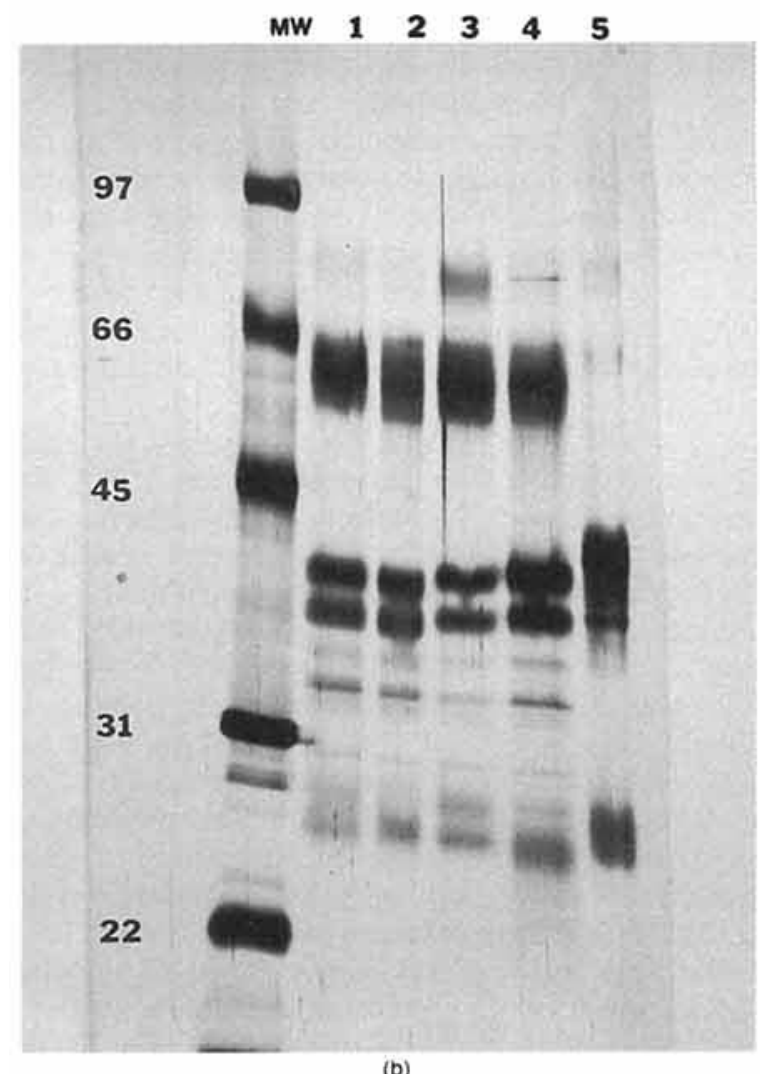

(b)

Figure 3. 9-18 per cent Silver stained SDS PAGE of purified pH 10 products: (a) non-reduced samples; (b) reduced samples. Lane 1: 115-6; lane 2: 83-1; lane 3: 110-1; lane 4: 122-5; lane 5: hPC reference from plasma. major subpopulations visible as distinct bands in the purified products of 115-6, 83-1 and 110-1 (Fig. 3a, lanes 1,2 , and 3, respectively). This heterogeneity ranges in $M_{r}$ from about $55 \mathrm{kDa}$ to about $66 \mathrm{kDa}$ for the rhPC populations and about $55 \mathrm{kDa}$ to about $68 \mathrm{kDa}$ for $\mathrm{hPC}$. Two major populations are seen in the non-reduced products from the milk of the higher rhPC-expressing animal, 122-5. In all cases, the apparent $M_{r}$ of the majority of the rhPC populations is about $2-5 \mathrm{kDa}$ lower than the analogous forms of hPC. The reduced products in Figs $3 \mathrm{~b}$ and 4 show that, unlike hPC, about $40-50$ per cent of the rhPC produced in all the pigs is of the single-chain form. Only about 5-10 per cent of the hPC appears as single-chain form (Fig. 3b and 4 ; lanes 5 and 10 , respectively). All three gross forms of the putative heavy chain appear in all the rhPC products; alpha, beta and gamma heavy chains. The light chain of the rhPC products also ran at a lower $M_{r}$ of about $25 \mathrm{kDa}$ for rhPC relative to about $25-28 \mathrm{kDa}$ for $\mathrm{hPC}$. More heterogeneity was seen in the light chain of hPC.

The percentage of the total rhPC bound that eluted in the $25 \mathrm{~mm} \mathrm{CaCl}$ from the 7D7B 10 column is given in Fig. 5 . Approximately 33 per cent of the rhPC bound from the $\mathrm{pH}$ 10 product from the milk of animal 115-6 eluted in the calcium fraction from the 7D7B 10 column. About 22 per cent of rhPC cfrom the pH 10 product of animal 110-1, 20 per cent from animal 83-1 and 10 per cent from animal

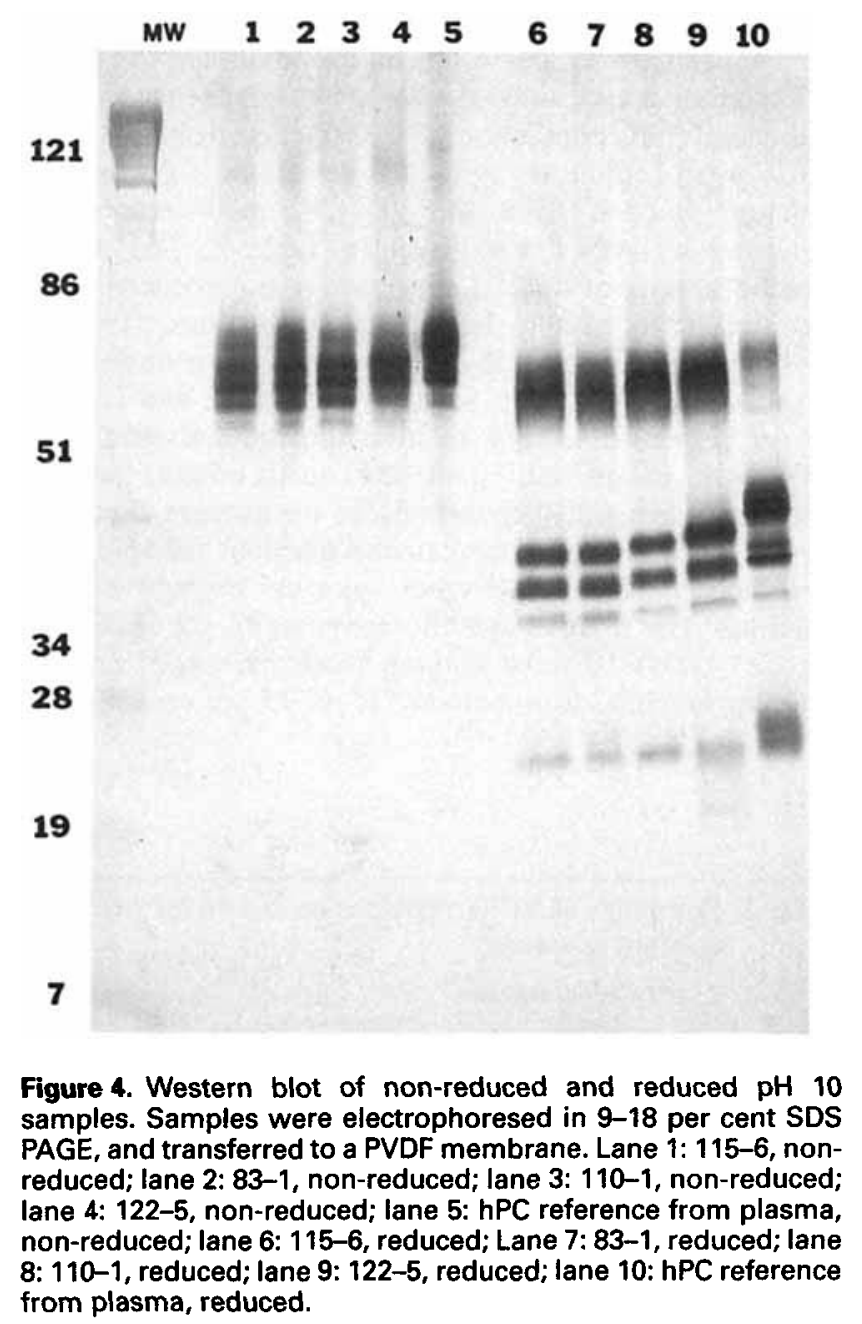




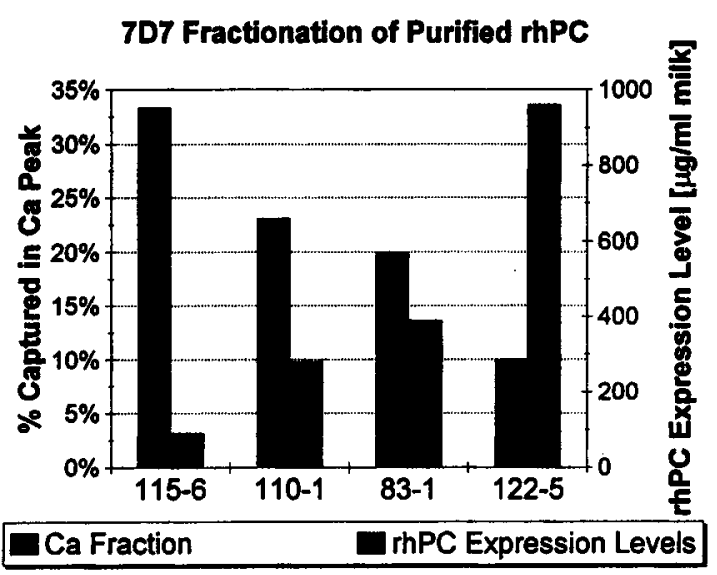

Figure 5. 7D7B10 fractionation of the $\mathrm{pH} 10$ products. A 7D7B10 immunoaffinity column was overloaded with purified rhPC from the $\mathrm{pH} 10$ fractions. The amounts of rhPC that eluted in the calcium peak and the $2 \mathrm{M} N \mathrm{NaSCN}$ peak were quantitated by ELISA. The percentage of bound rhPC eluting in the calcium peak is reported here.

122-5 eluted in the calcium fraction from the 7D7B10 immunosorbent. Fig. 5 also shows the average daily rhPC expression level, and the percentage of calcium-dependent conformer population are roughly inversely proportional to the average daily expression level in milk.

The relative specific biological activities for the majority of the total rhPC population (pH 10 fraction from the 12A8$8861 \mathrm{mAb}$ column) and the calacium subpopulation (calcium fraction from the 7D7B10 mAb column) as measured by APTT are given in Table 2 . The relative specific activity of rhPC is expressed as a percentage of the specific activity of hPC. For the pH 10 fractions, $115-6$ had the highest relative specific activity of 35 per cent, followed by $110-1$ at 28 per cent, 83-1 at 16 per cent and $122-5$ at 13 per cent of hPC. The relative specific activities of the rhPC from the $\mathrm{pH} 10,12 \mathrm{A8}-8861-\mathrm{mAb}$ column products were about inversely proportional to the average expression levels. The activities of the calcium fractions for all the pigs were higher than the activities from the respective $\mathrm{pH} 10$ fractions. The relative specific activities of the rhPC from the $\mathrm{Ca}^{2+}-7 \mathrm{D} 7 \mathrm{~B} 10 \mathrm{mAb}$ column products ranged from 67 per cent for rhPC from animal 115-6, 75 per cent for thPC

Table 2. Summary of APTT activities measured for pH 10 and calcium fractions ${ }^{\star}$

$\begin{array}{lccc}\begin{array}{l}\text { Pig } \\ \text { no. }\end{array} & \begin{array}{c}\text { APTT activity of pH10 } \\ \text { fraction } \\ \text { (\% of hPC in NPRP) }\end{array} & \begin{array}{c}\text { APTT activity of } \\ \text { calcium fraction } \\ (\% \text { of } h P C \text { in NPRP) }\end{array} & \begin{array}{c}\text { Average rhPC } \\ \text { expression level } \\ (\mu \mathrm{g} / \mathrm{ml})\end{array} \\ 115-6 & 35 \pm 1 \% & 67 \pm 3 \% & 90 \\ 110-1 & 28 \pm 2 \% & 81 \pm 7 \% & 280 \\ 83-1 & 16 \pm 2 \% & 160 \pm 26 \% & 390 \\ 122-5 & 13 \pm 1 \% & 75 \pm 3 \% & 960\end{array}$

*Activities are reported assuming values of $1 \mathrm{U} \mathrm{hPC/mI} \mathrm{NPRP}$ (250 U/mg hPC). from animal 122-5, 81 per cent for rhPC from animal 110-1 to 160 per cent for rhPC from animal 83-1.

\section{Discussion}

The first objective of this study was to purify the majority of the rhPC population from milk without significant yield losses. Porcine milk is a complex, multiphase mixture, and a challenging feedstock to process (Wilkins and Velander, 1992). Ultracentrifugation and other casein-precipitating steps were not used, as this results in a significant loss of rhPC in the casein pellet (Drohan et al, 1994b and unpublished observations). Instetad, the casein micelles were solubilized with EDTA, and the milk/EDTA mixture was centrifuged to remove the milk fat. The rhPC was eluted from the ion-exchange column with a $0.25 \mathrm{M} \mathrm{NaCl}$ buffer. In previous studies, this salt eluate was diluted to a lower ionic strength and then loaded on to a 12A8-8861 mAb column (Morcol et al., 1994). However, silver strain SDS PAGE of the resulting $\mathrm{pH} 10$ product showed about 10-20 per cent contamination by caseins. In an effort to discover what type of non-specific interactions were causing this contamination, the ionic strength of the $0.25 \mathrm{M} \mathrm{NaCl}$ eluate was left unchanged and loaded directly on to the 12A8-8861 mAb column. Apparently, ionic interactions between the caseins and the rhPC and/or the immunoaffinity column were responsible for the casein contamination, as the increased ionic strength resulted in a much more pure pH 10 product (Figs $2-3$ ). However, increasing the ionic strength of the immunoaffinity feed appeared to yield slower binding kinetics, as about 10-20 per cent of the rhPC population passed through the column. The remaining yield losses for the process (about 10 per cent) were from rhPC that remained tightly bound to the immunosorbent and eluted in the $2 \mathrm{M} \mathrm{NaSCN}$-cleaning step of the column. No further characterization of the rhPC in the 12A8-8861 immunoaffinity fall through or the NaSCN fractions was done for this study.

The 7D7B $10 \mathrm{mAb}$ was developed for gentle elution conditions needed for large-scale purification of hPC from plasma (Velander et al., 1990). Non-specific protein-protein interactions between rhPC, milk proteins and/or the 7D7B10 immunosorbent resulted in prohibitively slow adsorption kinetics and very low yields of rhPC when loading a crude feed (milk/EDTA and the $0.25 \mathrm{M} \mathrm{NaCl}$ DEAE eluate) on the 7D7B 10 column. In contrast, the adsorption kinetics of rhPC on to the $12 \mathrm{A8}-8861 \mathrm{mAb}$ immunosorbent were much faster and greater yields of rhPC were obtained. The rhPC was therefore first purified using the 12A8-8861 mAb immunosorbent, and then further fractionation of active from inactive populations was done using the 7D7B $10 \mathrm{mAb}$ immunosorbent.

A pure, biologically active fraction of the $\mathrm{pH} 10$ population was obtained by immunofractionation with the calcium-dependent mAb 7D7B10 (Table 2). The 7D7B10 binds protein $C$ in the presence of EDTA and releases protein $\mathrm{C}$ via a conformational change of the epitope (residues 1-15 of $\mathrm{NH}_{2}$-terminus of the light chain) in the presence of calcium. Fully $\gamma$-carboxylated hPC from plasma was shown to have a calcium-dependent interaction with 
7D7B10 (Orthner et al., 1989). The percentage of rhPC eluted in a calcium dependent manner was inversely proportional to the average rhPC expression level during the respective lactations (Fig. 5). These data indicate that a higher synthesis rates (beginning at about $1 \mathrm{mg} / \mathrm{ml}$ milk), the biosynthetic machinery of the mammary epithelial cells is unable to fully $\gamma$-carboxyate $\mathrm{Glu}^{6}, \mathrm{Glu}^{7}$, and/or $\mathrm{Glu}^{14}$ in as much as 90 per cent of the secreted rhPC. This corresponds to a per cell synthesis rate of about $10-20 \mathrm{pg} / \mathrm{cell} / 24 \mathrm{~h}$ (Morcol et al., 1994). Furthermore, the calcium-dependent fractions of rhPC from each pig either approached 70-80 per cent of the functional activity of hPC from a plasma reference pool (for rhPC from animals 115-6, 11-1, 122-5), or were hyperactive at about 160 per cent of reference hPC activity (for rhPC from animal 83-1). Thus, the calciumdependent mAb immunosorbent was capable of selectively eluting the most active population of rhPC.

The yields and specific activities of the rhPC from either the immunopurification process or the previously reported multistep precipitation/ion-exchange process (Drohan et al., 1994b) were similar for the same source milk. However, this immunoaffinity chromatographic process is more amenable to scale-up than the process based on multiple precipitation, centrifugation, filtration, and solubilization steps. An affinity chromatographic-based purification process such as presented here eliminates the need for multiple time-consuming, labor-intensive, low-resolution steps.

The authors included in this study four pigs representing four different genetic lines of transgenic pigs, each having a steady expression level of rhPC throughout a normal and healthy lactation. The range of $\mathrm{rhPC}$ expression in these pigs covers a full order of magnitude: $100-1,0000 \mu \mathrm{g} / \mathrm{ml}$ milk. The rate limitations for post-translational modifications can be studied here due to the wide range of expression levels in the porcine mammary gland coupled with the numerous post-translational modifications of fully processed hPC. The authors have previously shown that $\gamma$ carboxylation is rate limiting in the expression of rhPC in transgenic mice at lower expression levels (Paleyanda et al., 1995).

A number of studies have investigated the contributions of various domains of hPC to its anticoagulant activity (Mesters et al., 1991, 1993a and 1993b). In this work the authors focused on the 'gla domain', located in the first 29 residues of the $\mathrm{NH}_{2}$-terminal of protein $\mathrm{C}$ (Fig. 1). In fully $\gamma$-carboxylated hPC, all nine glutamic acid residues in this region are $\gamma$-carboxylated. The gla residues bind $\mathrm{Ca}^{2+}$ ions, enabling hPC to interact with endothelial phospholipids. An hPC molecule with a non-existent gla domain (Esmon $e t$ al., 1993), or a site-specific mutated gla domain (Glu'Glu $^{7} \rightarrow$ Asp $^{6}-$ Asp $^{7}$; Zhang and Castellino, 1990) all show greatly reduced activation rates and biological activities. The mAb 7D7B 10 binds to residues 1-15 of the light chain $\mathrm{NH}_{2}$-terminus of $\mathrm{hPC}$ in the presence of EDTA, and releases hPC via a conformational change of the epitope in the presence of calcium (Orthner et al., 1989). This epitope contains three gla residues, including the critical gla residues $\mathrm{Gla}^{6}-\mathrm{Gla}^{7}$, identified by Zhang and Castellino (1990) as being essential to obtaining fully functional hPC. Calcium-dependent elution of protein $\mathrm{C}$ is not observed if the gla residues are not present, and harsh elution conditions (for example $2 \mathrm{M} \mathrm{NaSCN}$ ) must then be used to remove bound protein $\mathrm{C}$.

Silver stain SDS PAGE and analogous western analysis of the purified $\mathrm{pH} 10$ products show that a number of different populations of rhPC were produced, the majority having a lower $\mathrm{M}_{\mathrm{r}}$ than $\mathrm{hPC}$ (Figs 2-4). hPC contains about 14 per cent carbohydrate (Yan et al., 1990), and differences in the $M_{r}$ of $h P C$ subpopulations have been shown to be caused by different glycosylation patterns (Miletech and Broze, 1990). Four N-linked sites have been identified on $\mathrm{hPC}$, three in the heavy chain and one in the light chain. The reduced gel and western blot indicate that glycosylation patterns of the heavy chain of the rhPC samples is likely to be responsible for the heterogeneity seen in the non-reduced samples. This has been confirmed by silver stain SDS PAGE and analogous western analysis of deglycosylated rhPC (data not shown). Inspection of the gel and western blot of the reduced samples also reveals that the $\beta$ and $\gamma$ heavy chains for both hPC and hPC migrate with very similar $M_{r}$. As would be predicted from the greatest permutation in glycoform variants due to the presence of three potential Nlinked glycosylation sites, it is the putative $\alpha$-chain of rhPC having that shows the greatest difference in $M_{r}$ to that of hPC.

Heterogeneity in the rhPC light chains is visible, but is not as signifcant. Propeptide cleavage, differing glycosylation and the extent of $\gamma$-carboxylation can be causes of these differences between light chain forms. Amino terminal sequencing shows that propeptide is not removed in about 20 per cent of the rhPC forms (data not shown). The majority of the rhPC light chains migrate with a $\mathrm{M}_{\mathrm{r}}$ of that of the smallest hPC light chain population, possibly due to different glycosylation of the light chain.

The products from this immunopurification scheme show the same amount of single-chain form: about $40-50$ per cent, as was found for differently purified rhPC reported in Drohan et al., (1994a). Immunofractionation using a different $\mathrm{mAb}$ to the activation peptide domain was able to separate some of the single-chain populations from mixed heterodimeric and single chain populations (Velander $e t$ al., 1992a). A rate limitation is indicated for post-translational cleavage of the dipeptide $\mathrm{Lys}^{156}-\mathrm{Arg}^{157}$ at all the expression levels studied here.

In conclusion, immunoaffinity chromatography using mAb can be a useful method of fractionating biologically active populations from the gross population of a recombinant protein. A purification process including a step such as this may be of great importance once recombinant proteins gain clinical approval for use as therapeutics. In addition, the use of a mAb directed towards an epitope containing a post-translationally modified portion of the protein can help identify rate limitations in the synthesis and secretion process. The authors postulate that the rate of $\gamma$-carboxylation is a key rate-limiting step in the synthesis of biologically active rhPC in the porcine mammary gland. This hypothesis is supported by the inverse relationship between the rhPC expression level and the calciumdependent rhPC-7D7B10 interaction and the high biological activity of the calcium-dependent fraction obtained from the 7D7B10 column. Further study will be done to characterize the carbohydrate moieties, amino acid sequences and gla-domains of rhPC from pigs with varying expression levels. This study indicates that while transgenic 
livestock can secrete complex recombinant proteins in milk at gram/liter levels, a significant fraction of the protein may be biologically inactive due to rate limitations in key posttranslational modifications.

\section{Acknowledgements}

This work was supported by a grant from the American Red Cross and NSF grant BCS-9011098. K. E. Van Cott was supported in part by the DuPont PhD Fellowship.

\section{References}

Comp, P. C. (1990). The clinical potential of protein C and activated protein C. In Protein $C$ and Related Anticoagulants, eds by D. F. Bruley and W. N. Drohan, pp. 181-186, Gulf Publishing Company, Houston, TX.

Drohan, W. N., Zhang, D.-W., Paleyanda, R. K., Chang, R., Wroble, M., Velander, W. and Lubon, H. (1994a). Inefficient processing of human protein $\mathrm{C}$ in the mouse mammary gland. Transgenic Res. 3, 355-364.

Drohan, W. N., Wilkins, T. D., Latimer, E., Zhou, D., Velander, W., Lee, T. K. and Lubon, H. (1994b). A scalable method for the purification of recombinant human protein $\mathrm{C}$ from the milk of transgenic swine. In Advances in Bioprocess Engineering, eds by E. Galindo and O. T. Ramirez, pp. 501-507. Kluwer Academic Publishers, Netherlands.

Esmon, C. T. (1985). The regulation of natural anticoagulant pathways. Science 235, 1348-1352.

Esmon, C. T. (1989). The roles of protein C and thrombomodulin in the regulation of blood coagulation. J. Biol. Chem. 264, 4743-4746.

Esmon, N. L., DeBault, L. E. and Esmon, C. T., 1983. Proteolytic formation and properties of $\gamma$-carboxyglutamic aciddomainless protein C, J. Biol. Chem. 258, 5548-5553.

Gelfi, C., Righetti, P. G. and Mannucci, P. M. (1985). Charge heterogeneity of human protein $C$ revealed by isoelectric focusing in immobilized $\mathrm{pH}$ gradients. Electrophoresis 6 , 373-376.

Grinnel, B. W., Walls, J. D., Gerlitz, B., Berg, D. T., McClure, D. B., Ehrlich, H., Bang, N. U. and Yan, S. B. (1990). Native and modified recombinant human protein C: function, secretion, and posttranslational modifications. Protein $C$ and Related Anticoagulants, eds. D. F. Bruley and W. N. Drohan, 29-63. Gulf Publishing Company, Houston, TX.

Heeb, M. J., Schwarz, H. P., White, T., Lammle, B., Berrettini, M. and Griffin, J. H. (1988). Immunoblotting studies of the molecular forms of protein C in plasma. Thromb. Res. 52, 33-43.

Kang, K., Ryu, D., Drohan, W. N. and Orthner, C. L. (1992). Effect of matrices on affinity purification of protein C. Biotechnol. Bioeng. 39, 1086-1096.

Mann, K. G. and Bovill, E. G. (1990). Protein C deficiency and thrombotic risk. Protein $C$ and related anticoagulants, eds. D. F. Bruley and W. N. Drohan, 119-123. Gulf Publishing Company, Houston, TX.

Martinoli, J. L. and Stocker, K. (1986). Fast functional protein C assay using Protac ${ }^{\circ}$, a novel protein $\mathrm{C}$ activator. Thrombosis Research 43, 253-264.

McClure, D. B., Walls, J. D. and Grinnell, B. W. (1992). Posttranslational processing events in the secretion pathway of human protein $\mathrm{C}$, a complex vitamin K-dependent antithrombotic factor. J. Biol. Chem. 267, 19710-19717.

Mesters, R. M., Houghten, R. A. and Griffin, J. H. (1991). Identification of a sequence of human activated protein $C$ (residues 390-404) essential for its anticoagulant activity. $J$. Biol. Chem. 266, 24514-24519.

Mesters, R. M., Heeb, M. J. and Griffin, J. H. (1993a). A novel exosite in the light chain of human activated protein $C$ essential for interaction with blood coagulation factor $\mathrm{Va}$. Biochem. 32, 12656-12663.

Mesters, R. M., Heeb, M. J. and Griffin, J. H. (1993b). Interactions and inhibition of blood coagulation factor $\mathrm{Va}$ involving residues 311-325 of activated protein C. Protein Science 2, $1482-1489$

Miletich, J. P. and Broze, G. J. (1990). $\beta$ protein C is not glycosylated at asparagine 329. J. Biol. Chem. 265, $11397-11404$.

Morcol, T., Akers, R. M., Johnson, J. L., Williams, B. L., Gwazdauskas, F. C., Knight, J. W., Lubon, H. L., Paleyanda, R., Drohan, W. N. and Velander, W. H. (1994). The porcine mammary gland as a bioreactor for complex proteins. Ann. NY Acad. Sci. 721, 218-233.

Subramanian, A., Van Cott, K. E., Millbrath, D. S. and Valender, W. H. (1994). Role of local antibody density effects on immunosorbent efficiency. J. Chromatogr. 672, 11-24.

Orthner, C. L., Mandurawe, R. D., Velander, W. H., Drohan, W. N., Battey, F. D. and Strickland, D. K. (1989). Conformational changes in an epitope localized to the $\mathrm{NH}_{2}$-terminal region of protein C. J. Biol. Chem. 264, 18781-18788.

Paleyanda, R. K., Russell, C. G., Chang, R. R., Johnson, J., Velander, W., Drohan, W. N. and Lubon, H. (1995). $\gamma$ Carboxylation of human vitamin K-dependent proteins in the mouse mammary gland. Proceedings of the 1995 Miami Bio/Technology Winter Symposium Short Reports, 6, 108.

Velander, W. H., Morcol, T., Clark, D. B., Gee, G. and Drohan, W. N. (1990). Technological challenges for large-scale purification of protein C. Protein C and Related Anticoagulants, eds. D. F. Bruley and W. N. Drohan, 11-27. Gulf Publishing Company, Houston, TX.

Velander, W. H., Johnson, J. L., Page, R. L., Russell, C. G. Subramanian, A., Wilkins, T. D., Gwazdauskas, F. C., Pittius, C. and Drohan, W. N. (1992a). High-level expression of a heterologous protein in the milk of transgenic swine using the cDNA encoding human protein $C$. Proceedings of the National Academy of Sciences USA, 89, 12003-12007.

Velander, W. H., Page, R. L., Morcol, T., Russell, C. G., Canseco, R., Young, J. M., Drohan, W. N., Gwazdauskas, F. C., Wilkins, T. D. and Johnson, J. L. (1992b). Production of biologically active human protein $C$ in the milk of transgenic mice. Annals of the New York Academy of Sciences 665, 391-403.

Wilkins, T. D. and Velander, W. (1992). Isolation of recombinant proteins from milk. J. Cell. Biochem. 49, 333-338.

Yan, S. C. B., Razzano, P., Chao, Y. B., Walls, J. D., Berg, D. T., McClure, D. B. and Grinnell, B. W. (1990). Characterization and novel purification of recombinant human protein $C$ from three mammalian cell lines. Bio/Technology 8, 655-661.

Zhang, L. and Castellino, F. J. (1990). A r-carboxyglutamic acid $(\gamma)$ variant $\left(\gamma^{6} \mathrm{D}, \gamma^{7} \mathrm{D}\right)$ of human activated protein $\mathrm{C}$ displays greatly reduced activity as an anticoagulant. Biochem. 29, 10828-10834. 